\title{
Plastic deformations under initial conditions of contact problem of mechanics (case study of riveted joints)
}

\author{
Kudryavtsev A.A. \\ Irkutsk National Research Technical University \\ Irkutsk, Russia \\ ksansan@yandex.ru
}

\begin{abstract}
The developed finite-element model of the assembly structure of a riveted joint can be used to a) calculate the stressstrain state of joint elements in elastoplastic forming, including rivet point formation; b) take into account residual stresses following elastoplastic deformation under external loading of the assembly structure. The article applies mathematical tools for solving the contact problem of the solid mechanics using a finiteelement method and transforming the global stiffness matrix. The matrix is based on the yield criterion and the state of contact finite elements. The elastoplastic model of materials with nonlinear hardening and the Coulomb-Siebel models of friction were applied. Simufact.forming and Marc were used as software tools. Stress fields with and without residual stresses were compared. The solution of the contact problem of elastoplastic material deformation was validated by comparing with experimental data of well-known researches.
\end{abstract}

Key words-assembly structure, contact problem, riveted joint, elastoplastic forming, residual stresses.

\section{INTRODUCTION}

Reliability of riveted joints in aircraft structures is one of the crucial factors influencing the flight safety. According to statistical data, most fatigue failures of aircrafts can be attributed to failures of riveted joints [1]. Figure 1 shows a riveted joint failure - a TU-154 fuselage skin fragment separation on the starboard side near the $32-37^{\text {th }}$ frames. This failure can be observed on the port as well. It is typical for all TU-154 aircraft models. This fact is one of the numerous examples of riveted joint failures.

Despite the long-term experience of using riveted joints in various machine-building industries, scientific and technical assessment of their capacity is a relevant task at the design and test stages due to poorly developed engineering and technological methods used for efficient and economically rational riveting and long-term riveted joint behavior analysis. The problem involves studying such phenomena as plastic deformations, creeping, residual stresses and their influence on the reliability and life-cycle of riveted joints. Riveted joints are assembly structures influenced by external factors. To obtain reliable engineering analysis results, interaction conditions have to be taken into account. It is difficult to simulate interaction conditions in the structures whose parts are susceptible to significant plastic deformations.

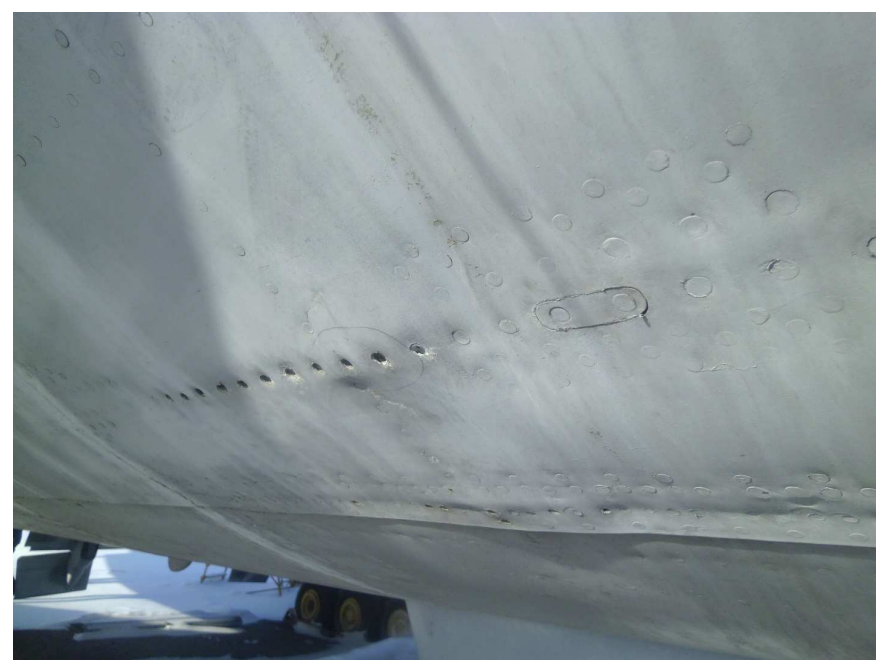

Fig. 1. Failures of TU-154 riveted joints

Strength properties of joints depend on the stress-andstrain state of their elements which are conditioned by structural joint parameters and riveting methods. The concept of the even external force and even stresses between joint points cannot provide a basis for searching for relations between joining parameters and life-cycle characteristics. It is well-known that the life cycle of riveted and bolted joints depends on axial and radial loads [2, 3]. Among other things, it depends on the geometry tolerance. Currently, there is a large base of experimental data. However, the functions of these tolerances are under-studied. The conclusions about the influence of the fitting on the strength and life cycle are contradictory. The issue of technological riveting parameters is also crucial [4]. Application of composite materials in aircraft structures makes this issue even more crucial.

The stress state of the sheet caused by load fitting is analyzed in many researches. The stress state is analyzed under plastic deformations. However, it is under-studied in case of elastoplastic deformations. Based on these works, it is impossible to calculate stress values for real joints. The studies are qualitative rather than quantitative analysis of the stress 
state $[2,5]$. Traditional approaches ignoring many significant factors cannot be used for determining design and technological parameters of more complex riveted joints. New methods for calculating the stress-and-state state of assembly structures can overcome this disadvantage.

\section{MODEL DEVELOPMENT}

Modern calculation tools of engineering analysis based on the finite-element method provide wider opportunities for process and product simulation. However, to apply them correctly, it is necessary to carry out some researches.

In particular, the elastic model of the material does not provide satisfactory results for calculation of the stress-andstrain state of assembly structure elements. The present research uses an elastoplastic model of materials with nonlinear hardening in the form of a tensile diagram. The model accurately describes the material behavior under plastic deformations and does not complicate the calculation. It is also assumed that the material is isotropic.

A simplified structure shown in Figure 2 is taken as a riveted joint. The model consists of seven elements and includes two sheet parts of $3 \mathrm{~mm}$ in thickness and three countersunk rivets of $5 \mathrm{~mm}$ in diameter. Besides, the model consists of two rigid dies in the form of rectangular blocks. The bottom die is fixed. The plates are installed on the lower die. The upper die moving in a vertical direction impacts rivet shank ends forming closing rivet heads.

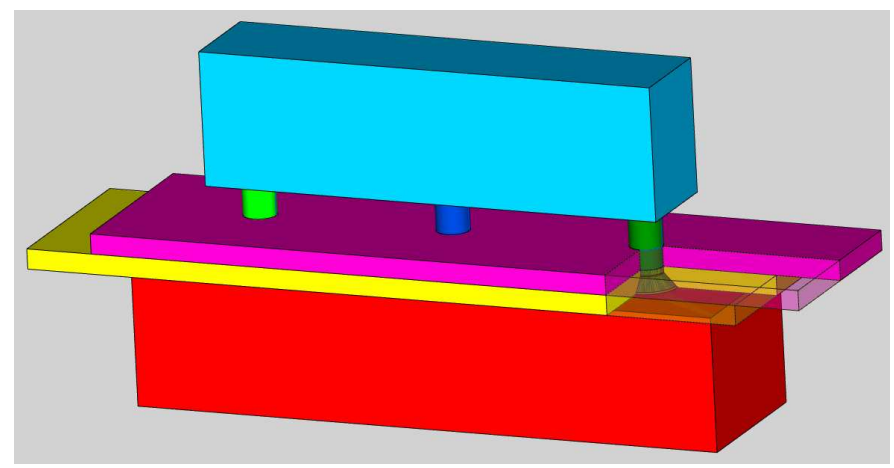

Fig. 2. The assembly structure of the riveted joint

Despite the fact that the rivet is a rotation body, the present article uses a model of the three-dimensional stress state because different distances to the sheet ends and neighbor rivets can distort the stress state of the axisymmetric position. It is evident that there are different stress components. Therefore, the yield condition as a stress tensor invariant function has to be taken into account [6]:

$$
f_{T}\left[I_{1}\left(T_{\sigma}\right), I_{2}\left(T_{\sigma}\right), I_{3}\left(T_{\sigma}\right)\right]=0 .
$$

As far as under uniform strain and compression, plastic deformations do not occur (the first stress deviator invariant is equal to zero), condition (1) can be presented as:

$$
f_{T}\left[I_{2}\left(D_{\sigma}\right), I_{3}\left(D_{\sigma}\right)\right]=0
$$

where $I_{2}\left(D_{\sigma}\right), I_{3}\left(D_{\sigma}\right)$ are stress deviator invariants.

Expression (2) is taken as a basis for calculation of elastoplastic deformations. The Mises criterion was used as a yield criterion. It says that yielding occurs when the second stress tensor invariant reaches a critical value. It is described by the following expression:

$$
\left(\sigma_{1}-\sigma_{2}\right)^{2}+\left(\sigma_{2}-\sigma_{3}\right)^{2}+\left(\sigma_{3}-\sigma_{1}\right)^{2}=2 \sigma_{T}^{2}
$$

where $\sigma_{1}, \sigma_{2}, \sigma_{3}$ - principal stresses;

$\sigma_{T}-$ yield stress of tension or compression.

Expression (3) is an energy condition of initial yielding. It can be used along with a deformed system potential energy minimization principle which is a basis for solving solid mechanics problems using the finite-element method (FEM).

The general equation of mechanical equilibrium is as follows:

$$
[K]\{\delta\}=\{F\}
$$

where $[K]$ - stiffness matrix;

$\{\delta\}$ - displacement vector;

$\{F\}$ - force vector containing external loads and contact forces of interacting elements of the assembly structure.

When solving tasks taking into account physical nonlinearity of materials, the force vector can be presented as:

$$
F(\{\sigma\},\{\varepsilon\})=0
$$

where $\{\sigma\}-$ stress vector;

$\{\varepsilon\}$ - deformation vector.

Using the linear law of elasticity, one can write:

$$
\{\sigma\}=[D]\left(\{\varepsilon\}-\left\{\varepsilon_{0}\right\}\right)+\left\{\sigma_{0}\right\}
$$

where $[D]$ - elasticity matrix (material tangent);

$$
\begin{aligned}
& \left\{\varepsilon_{0}\right\} \text { - initial deformation vector; } \\
& \left\{\sigma_{0}\right\} \text { - initial stress vector. }
\end{aligned}
$$

The general solution has to satisfy equations (4), (5) and (6). It is reasonable to use an iterative method with variations, elastic characteristics, initial deformations or initial stresses [7]. $\quad \alpha+\beta=\chi$. (1) (1)

When in deformation, contact rigidity and contact surfaces of interacting elements of the assembly structure can change. It is an inherent task of the forming process. To this end, the iteration principle and variable rigidity method can be used despite high calculation cost because they transform the global

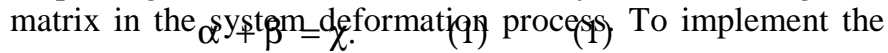


iteration principle, the Newton-Raphson method and the contact element of the structure interaction described in $[7,8$, 9] were used. Vector $\{F\}$ is applied in portions. After each addition, two conditions were checked:

- the conditions of plastic deformations by the Mises criterion;

- the state of contact finite elements.

Based on the checking results, the global stiffness matrix is transformed and matrix [D] is modified if required [7].

The friction model which is applied in a combined version is important for analysis of assembly structures. The Coulomb's law is applied when the stress value is lower than the yield limit. The Siebel's law is applied when the stress value is higher than the yield limit.

Thus, many interdependent factors characterizing the material state are taken into account when calculating the stress-and-strain state of the riveted joint: stresses in contact zones, shapes and sizes of contact zones, changes in shapes and stresses. All these factors are taken into account in the elastoplastic model when setting the rivet. It provides a more complete picture of stress fields distribution in comparison with old elastic models. To solve the task, Simufact.forming and Marc were used.

\section{ANALYSIS OF ELASTOPLASTIC MATERIAL DEFORMATION SIMULATION RESULTS IN RIVETING}

The fields of equal Mises stresses (hereinafter stresses) and displacements presented in Fig. 3, 4, 5 and 6 were determined using calculations of the riveted joint model.

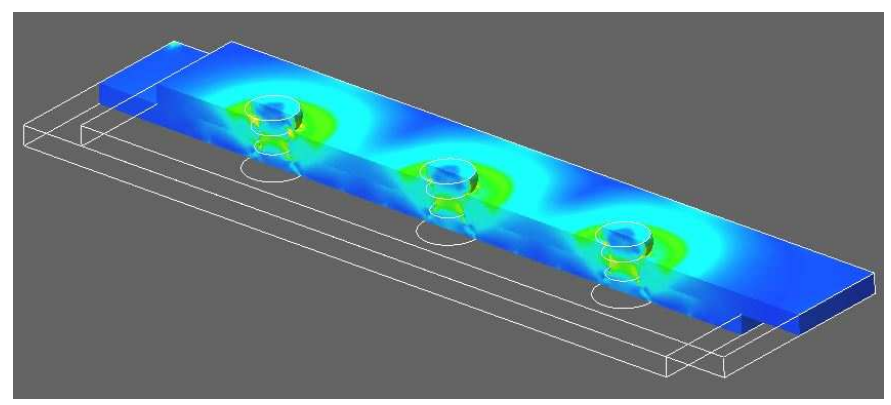

Fig. 3. The stress field after riveting.

The results are in compliance with the stress-and strain state of the assembly structure after riveting and removing die loads.

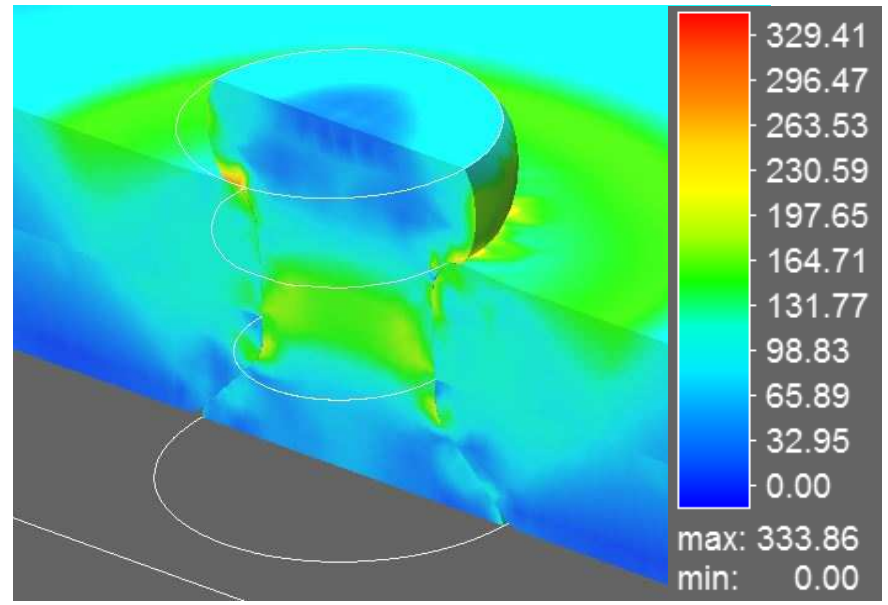

Fig. 4. The stress field in the rivet-plates contact area, MPa.

Fig. 3 and 4 show the complex nature of stress distribution. The stresses near the contact surfaces have high gradients. The highest gradient can be observed in the closing head-sheet area and in the area where the cylindrical part transforms into the conic one.

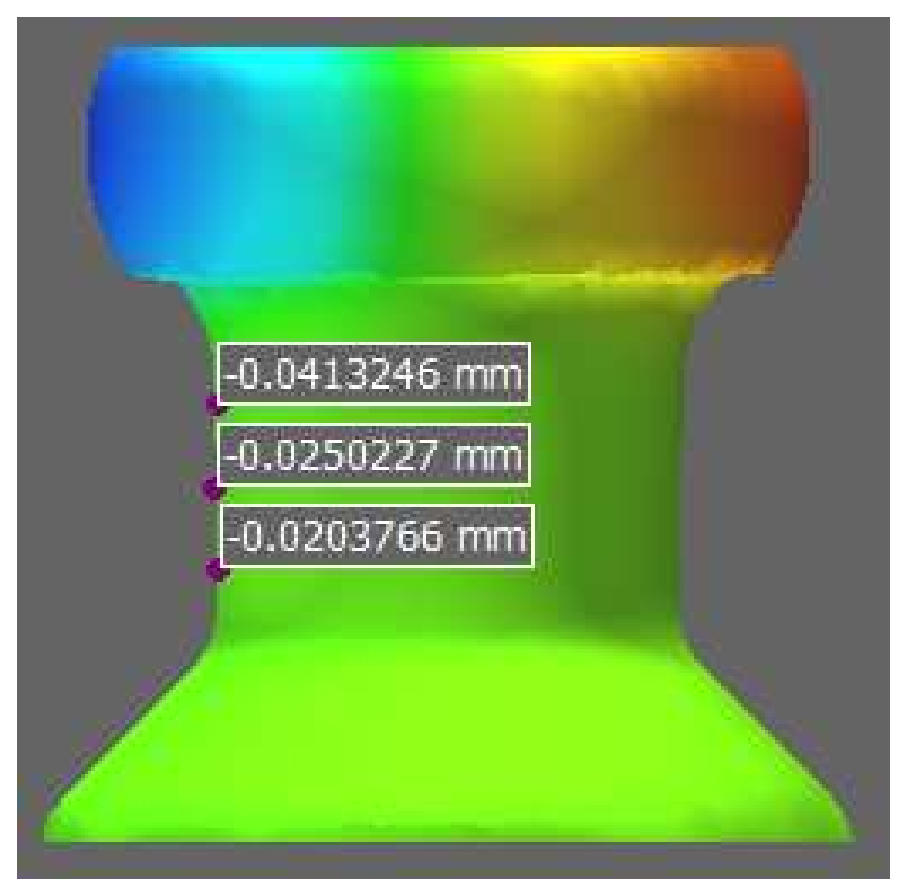

Fig. 5. The radial displacement field in the rivet, $\mathrm{mm}$.

Fig. 5 shows that radial displacements of the points along the rivet body have different height values. These data speak for a conicity of the rivet body due to uneven material deformation. The closing head is more deformed than the primary one. The top of the cone faces the primary head. This effect is well-known. It was proved experimentally. It speaks for the calculation model adequacy.

The stress field in Fig. 6 is of special interest. 


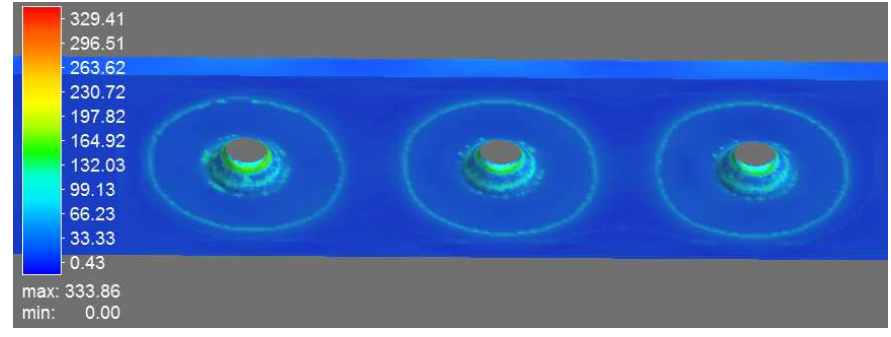

Fig. 6. The stress field on the countersunk sheet surface after removing die loads, $\mathrm{MPa}$.

Concentric circles in Fig. 6 are stresses increasing up to 70 $\mathrm{MPa}$. These stresses are residual as far as the dies do not exert pressure. Fig. 7 shows that such circles are absent at the previous calculation stage.

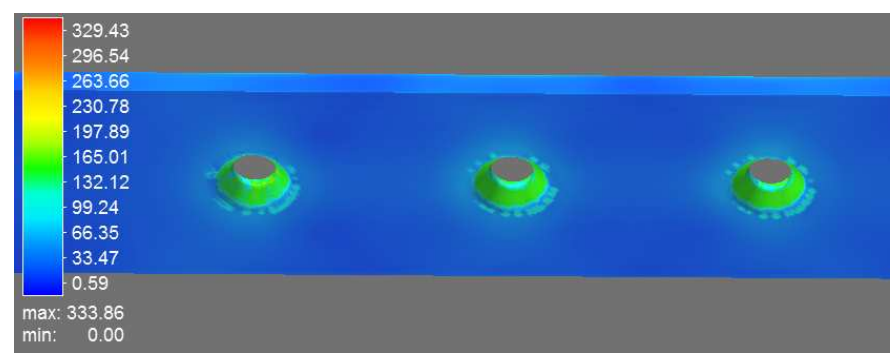

Fig. 7. The stress field on the countersunk sheet surface before removing die loads, $\mathrm{MPa}$

These circles may appear due to bended sectors around the rivets. As far as in closing rivet forming, the conical part of the rivet exerts pressure on the plates, the sectors of the bottom sheet around the rivets experience bending. Fig. 8 shows the values of normal direction displacements, i.e. there are cavities from the underside of the sheet (from the side of primary heads).

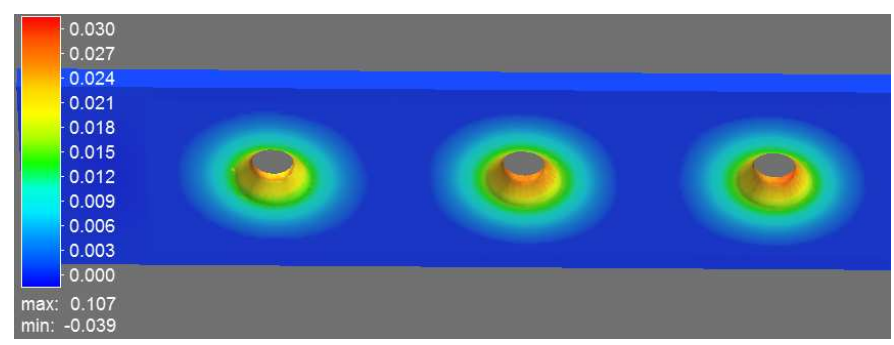

Fig. 8. The normal direction displacement field, m.

Cavities occur under production conditions as well which speaks for the correctness of the calculation model.

\section{ANALYSIS OF SIMULATION RESULTS FOR THE RESPONSE OF THE STRUCTURE RESPONSE TO EXTERNAL LOADING}

Previous calculations determined residual stresses and deformations resulted from closing head forming. These data were used as initial conditions when calculating the structure under external loads.
The force of $7 \mathrm{kN}$ shifting sheets and directed along the joint was taken as an external load. This calculation was carried out using a step-by-step load increase principle and the Newton-Raphson method. Fig. 9 and 10 show changes in the stress field in the longitudinal section of the structure with/without external force effects. The evaluation scale was the same for all Figures. It is presented in Fig. 9.

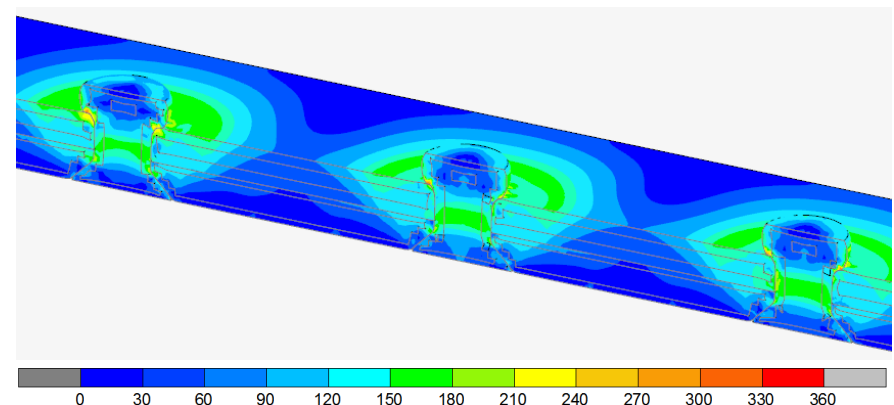

Fig. 9. The longitudinal stress field without external loading, MPa.

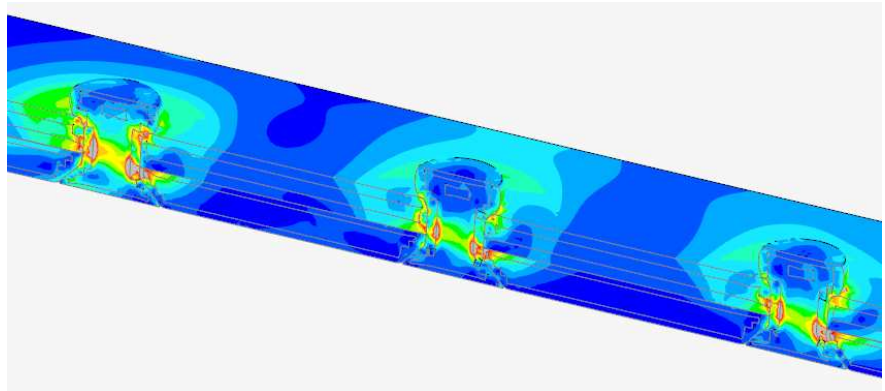

Fig. 10. The longitudinal stress field with external loading, MPa.

Fig. 10 shows the zones of significant stresses near the rivet body-sheet contact area. Fig. 11 shows the stress field in the area of the center rivet under external loading.

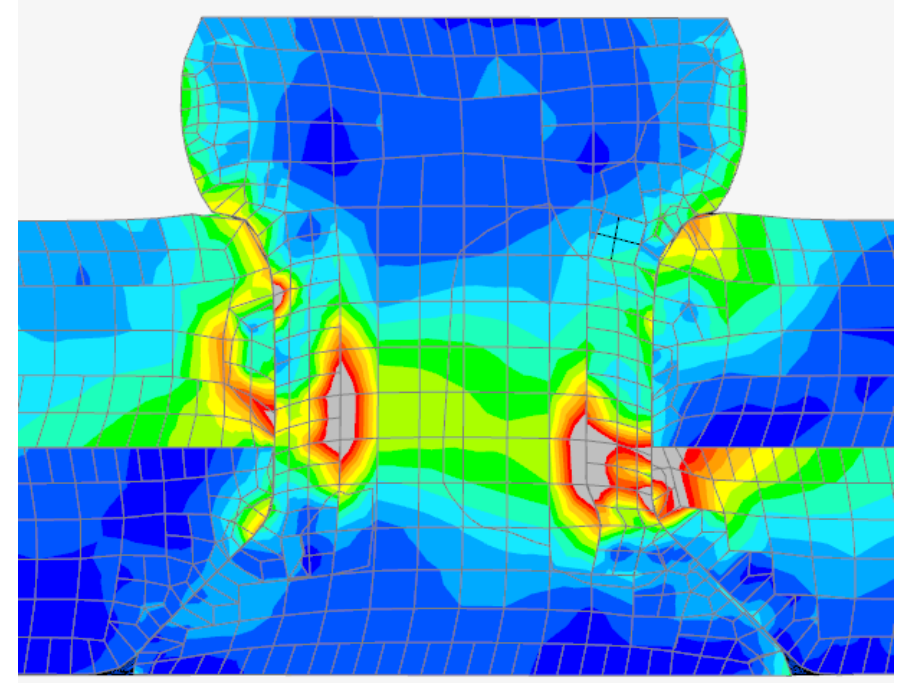

Fig. 11. The longitudinal stress field in the center rivet, MPa. 
To see the difference of the stress field under external loading, the model was calculated under the same external loads but disregarding the initial conditions. The results of this calculation are shown in Fig. 12 and 13.

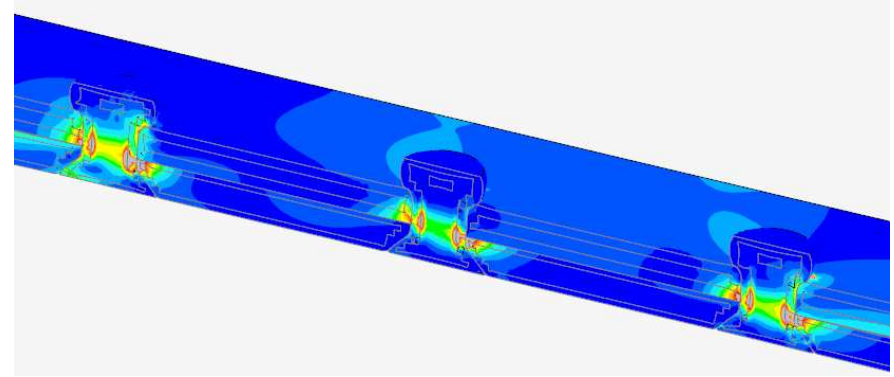

Fig. 12. The longtiduninal stress field under external loading disregarding the initial conditions, $\mathrm{MPa}$.

Fig. 12 shows that stresses in the sheets which are distant from the rivets and in the closing and primary dies are lower than in the case shown in Fig. 10. However, the difference of stresses in the cross-sections of closing and center rivet bodies is more significant. In general, the nature of stress distribution in the rivets speaks for the fact that the closing rivets are under the larger external loading than the center one. This irregularity in distribution of the shear load between connection points of the joint is well-known [10] from experimental researches. The similar calculation results speak for the model adequacy. Fig. 11 and 13 also show similar longitudinal distribution of stresses. It can be noted that in Fig. 13 , the zones with low stresses are wider, and transitions to the zones with heavy stresses are sharper. Fig. 11 shows that stresses in the connection elements are more uniform despite the same concentrations.

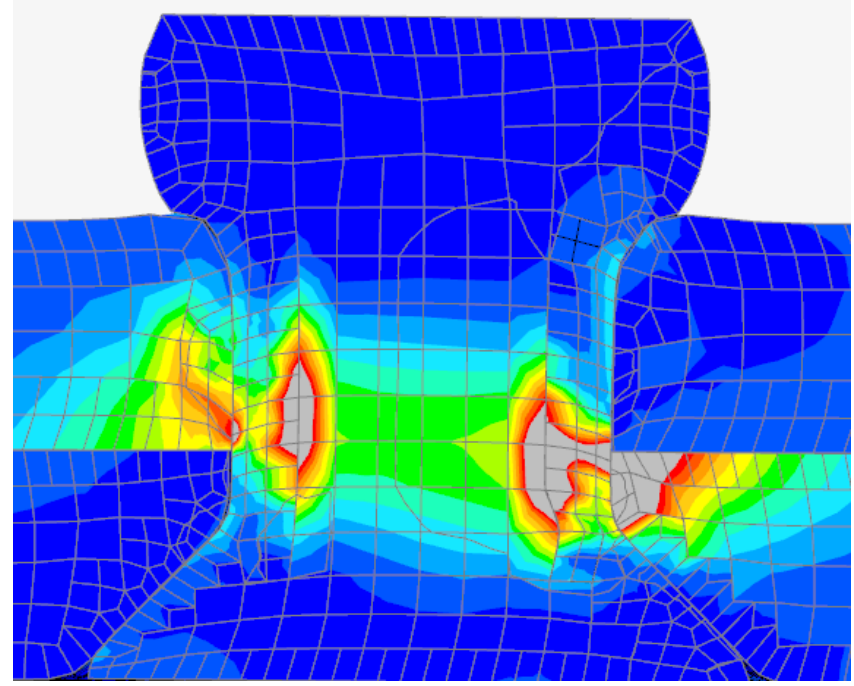

Fig. 13. The longitudinal stress field in the center rivet (the calculation disregards the initial conditons), MPa field.

Fig. 14 and 15 show a more striking result in the stess 
practical possibility of more accurate identification of stresses in riveted joint elements under operating conditions. This specifying condition is required for development of a modern method for designing riveted joints in order to develop new engineering solutions [11].

\section{References}

[1] Yu.A. Vashukov, O.V. Lomovsky, A.A. Sharov, Technology and equipment of assembly processes. Samara: Samara State Aerospace University n.a. S.P Korolyov, 2011.

[2] V.P. Grigoriev, Influence of the sheet joining technology on parts strength and endurance. Moscow: Oborongiz, 1963.

[3] А.И. Yarkovets, О.S. Sirotkin, V.A. Firsov, N.M. Kiselev, The technology for making durable riveted and bolted joints in aircraft structures. Moscow: Mashinostroenie, 1987.

[4] E. Knyazev, S. Sergievsky, "Computer modeling of making riveted joints for aviation structure elements using Simufac"t, CADmaster, vol. 3(85), pp. 41-43, 2016.
[5] V.P. Grigoriev, Assemblage of valve units of airplanes and helicopters. Mowcow: Mashinostroenie, 1974.

[6] N.N. Malinin, Applied theory of plasticity and creeping. Mowcow: Mashinostroenie, 1975.

[7] A.A. Pyhalov, A.E. Milov, Contact problem of static and dynamic analysis of the assembly rotors of turbomachines. Irkutsk: ISTU, 2007.

[8] M.A. Dudayev, A.A. Pyhalov, "Contact problem in the analysis of dynamic behavior of turbomachine rotor assemblies", Novosibirsk, Scientific Bulletin of Novosibirsk State Technical University, vol. 3(60), pp 113-12, 2015.

[9] A.A. Kudryavtsev, "Contact heat conductivity and the finite element method in the problem of heat stress analysis of assembly structures", in "Modern technologies. System analysis. Modeling". Irkutsk, 2011, pp. 68-73.

[10] V.F. Kozhevnikov, "Distribution of forces and stresses along rows of bolted joints", CAHI Scientific Notes, vol. 10, pp. 134-139., 1979.

[11] A.G. Gromashev, Technological design of durable riveted and bolted joints. Issues of aircraft construction. Kiev: Publishing company "KIT", 2007. 